\title{
The Application Study on Computer Aided Design in Construction
}

\author{
Modeling \\ Sheng Zhang Chang-juan Chen \\ Jiangxi Institute of Fashion Technology, Nanchang 330201, Jiangxi Province, China \\ E-mail: 93660095@qq.com
}

Keywords: Computer aided design, Construction modeling, Application

\begin{abstract}
The paper focuses on the discussion of specific application of computer technology in the construction modeling. From the paper we know that the application of computer aided design to modeling has been quite mature in the process of current market operation, but it seems to be less consistent and flexible in the teaching process of colleges and universities. Furthermore, some college teachers just blindly follow suit in teaching, and don't realize the primary and secondary relationship between construction modeling and computer aided software and the combination of the two skills in essence.
\end{abstract}

\section{Introduction}

The course of construction modeling is an important component of the course construction of contemporary art colleges, which can train students' ability of three-dimensional thinking, design and using materials. With the market demand of social real estate development, exhibition, urban planning and so on, construction models have changed a lot from design to production, so it is difficult to see the traditional mode of handicraft workshop. However, nowadays computer software has been very popular in colleges and universities, and has been constantly updated and developed. It can also be considered that the application of computer aided software brings the construction modeling a qualitative leap from design to production. Therefore, colleges and universities should incorporate the computer aided software into the course of model building, and also make it one of the skills that students must master.

\section{The role of computer aided software in the teaching process of specialized courses}

With the constant development of society and the increasing maturity of university, the extensive application of computer aided software has made the expression of contemporary design ideas more convenient and faster, and also freed the designers from the traditional painting, so they can show the conception in their minds and the creative inspiration from observation to the world in the fastest way, and even enable customers to understand design scheme in a visual way. Therefore, the application of computer aided software makes it possible that the designers can express their design ideas in a fast way and makes their design thinking and design work unified and consistent.

In the current teaching process of the university, I think computer aided curriculum needs to be deepened and reformed, which can not be regarded as one or more software courses. If we use the computer aided software as a common drawing tool, which is taught and learned 
for the sake of drawing, then it is much like that a designer treats the pen and ruler as tools. Such understanding is not profound enough in my opinion. This indicates that there exists the problem of communication gap among the curricula and messy knowledge structure. The single teaching curriculum arrangement is not reasonable, and some schools even eliminate the course, so I think it results from the lack of understanding, and also it does not treat the overall layout of the professional courses according to the teaching principle of applying what one has learned and integration. Therefore, the best solution to the single form of computer aided curriculum and boring teaching is to adopt various teaching forms and integrate the course of computer aided design into the professional course. Teachers should communicate with each other and the teaching should proceed consistently and synchronously, so that the classroom teaching can combine with activities after class, and achieve unity with the review after class.

\section{Experience of the application of computer aided software in the teaching process}

According to the syllabus of the college, the computer aided software includes AUTOcad, 3DMAX, Photoshop, VR and so on. These courses are carried out step by step, which mainly intend to cultivate students' practical ability and auxiliary function. Through the research and experiment of the subject, I have applied these comprehensively on purpose and introduced them into the professional courses cleverly, thus combining the "learning" and "practicing" organically. To be specific, solving the problem step by step refers that in the teaching process, first teachers explain the contents of the chapter in detail, and then students practice according to the project.

It can be divided into four steps specifically: the first step, the demonstration teaching of teachers. It should pay attention to the interaction between teachers and students, mobilize students' enthusiasm and expound the base component thoroughly; the second step, the computer practice of students. It is better to be centralized training. Teachers should guide students and make supplement and correct guidance, so that students get started quickly, and understand the teaching content thoroughly; the third step, the teacher should improve the professional drawing knowledge of the software by adopting illustrating teaching method, so that students integrate the software knowledge into professional courses; the fourth step, some propositions should be given to students for independent practice. Then the teacher makes comments, and students give the feedback, thus resolving the deficiencies. With years of teaching practice, I have summed up the four steps of teaching which is a good solution to the software learning effect of students. It has corrected students' misunderstanding of software, solved the disconnection of teaching and learning in the teaching process, shortened the time that students take to grasp the knowledge of software and improved the teaching quality of other professional courses.

\section{The application of course interactive teaching of computer aided design and construction modeling}

In view of the current teaching in domestic universities, I believe that the connection and interaction among curricula should be regarded as an important link. We should pay attention to the interaction among the curricula, thus optimizing the teaching quality to the largest extent. 
(1) In the process of course interactive teaching of computer aided course and construction modeling, the advantages of computer aided software should be given full play, which can not be conducted only for the sake of supporting. Besides, the two are interactive and inclusive. The computer aided design should complement rather than replace the construction modeling when it is successfully introduced to construction model design course. Now the curriculum development of colleges and universities has been mature, and after years of verification, the kernel structure of traditional teaching method is reasonable, whose incidental original requirements and necessity of knowledge structure can not be discarded. For example, the expression of design ideas is achieved through sketches, drawings, multimedia and language, and the traditional drawing tools play a decisive role. The students must master these knowledge, and it is wrong to discard the basic knowledge. The introduction of computer aided course into the modeling course is not to discard or overthrow the original mode of education, but to maintain the original foundation, constantly innovate and develop, thus enabling the knowledge structure more reasonable and the teaching effect more significant. If the students rely on computer aided software excessively, they will discard the basic expression foundation of design. However, the design idea, engineering drawing, structure performance and appearance display are still the most basic skills of a good construction modeler. If the design is mixed with computer graphics, the students will not be able to grasp the overall design thinking of construction model accurately and create good designs. Therefore, attention should be paid to time and proportion when computer aided design is introduced to the course of construction model.

(2) Computer aided design is a drawing tool. The introduction of computer aided software to construction modeling must pay attention to the way and method. In the previous teaching process, some students lay great emphasis on the production of design sketch, but ignore the important contents from the model design to the process. In view of this phenomenon, teachers should give proper guidance and can not reverse the primary and secondary. Therefore, in the course of construction modeling, computer aided design should focus on the process rather than the performance of result.

(3) In view of the characteristics of construction modeling course, we should grasp the interaction between computer aided design and modeling. 1. Course orientation: through systematic theoretical study, we should understand the structure characteristics of construction, basic knowledge and basic procedure of construction modeling; through the later practice, we should master the related ways and procedure of introducing computer aided software and build the model completely and independently; we should also have the awareness of team cooperation, work in groups and promote the modeling jointly. 2. The feasibility research of the design scheme: the entity or virtual display is the best form to express the design ideas finally. Therefore, we should be careful to confirm whether the design is scientific and operational, and also study it from the perspective of aesthetics. 3 . The construction drawing should be rigorous and standard: it is a rigorous and systematic process to work on the construction drawing. In the profession of environmental art, the construction drawing has its specialized software AutoCAD which is one of the most rapid and scientific means of construction drawing. We know that construction model is the copy of miniature of the construction. Using the concept of scale, we can simulate the real environment, thus achieving the best effect. For the conceptual or generic model, it is rather difficult to draw the graphics. Therefore, to solve the problems is to promote the level of computer software, so the 
two are interactive. 4. The production of design sketch: the display of design sketch is indispensable in today's interior and exterior design. The common manufacturing software of design sketch are 3DMAX and SketchUp, which can show the design ideas quickly and provide real effect to the work. Through the production of design sketch, we can also find the shortcomings, keep improving, and make the design ideas more scientific and aesthetic. At the same time, the design sketch not only shows the three-dimensional space, but also enhances the students' ability to perceive the space. The production of design sketch requires a very strong foundation of software, and through the interaction of curricula, the proficiency of software and the aesthetic ability of design can be achieved.

\section{Conclusion}

The application of computer aided design to modeling has been quite mature in the process of current market operation, but it seems to be less consistent and flexible in the teaching process of colleges and universities. Furthermore, some college teachers just blindly follow suit in teaching, and don't realize the primary and secondary relationship between construction modeling and computer aided software and the combination of the two skills in essence. From the perspective of the essence of teaching: construction modeling falls into the category of design, which is the subjective design thinking with strong purposiveness. While, computer aided software is a design tool, which belongs to the skill knowledge. It can never make judgments on behalf of human brain and design in replace of thinking. It is just a kind of tool in design, which does not have the elements of art design and aesthetic theory.

\section{Reference}

[1] Luo Zhihua, Li Xi. Analysis on the Application of Computer Sketching Technology in Architectural Design [J]. Industrial Architecture, 2005,35 (9): 32-34.

[2] Li Nianping; Zhao Shouqin; Zhang Xijian; Zhao Hongli; Discussion on the Supervision Construction and Decoration Engineering [A]; The Tenth Excellent Academic Papers of the Shandong Water Conservancy Institute [C]; 2005

[3] Wang Liping; The Application of Electronic Commerce in the Decoration Industry [D]; Beijing University of Posts and Telecommunications; 2006

[4] Liu Hongfeng, Liao Xiaofeng. The Application of SketchUp in the Teaching of Architectural Drawing [J]. Journal of Chongqing University of Science and Technology (Social Science Edition), 2008 (6): 184-185. 